\title{
ESCRITURA E SEU COMBATE: A FOLHA EM BRANCO
}

\section{READWRITING AND ITS COMBAT: THE BLANKET SHEET}

\author{
Sônia Regina da Luz Matos ${ }^{1}$ \\ Roger Andrei de Castro Vasconcelos ${ }^{2}$ \\ Camila Fátima Cavion ${ }^{3}$ \\ Alice Virgínia de Oliveira Pacheco ${ }^{4}$ \\ Rudinei Fernando Rech ${ }^{5}$
}

\begin{abstract}
Resumo: Foi no Seminário de Tópicos Especiais: Escrita e seu combate - a folha em branco, oferecido no decorrer do primeiro semestre de 2019 no PPGEdu/UCS, que surgiram textos que expressam-imagem-escrita. $\mathrm{O}$ combate ao cruel da folha em branco foi operado nas aulas com intervenções no universo denominado acadêmico. Barthes (2000), Deleuze (1997), Guatarri (1987) estiveram presentes neste jogo de afecção do ler devorando a escrita e escrever devorando a leitura. Esse jogo junto à folha em branco passa a funcionar como condições e possibilidades da solidão/silêncio, escritura e imagem-afecção, experimentações de escritura na aula que ensaiamos com a leitura e a escrita. Com essa experimentação, movimentamos a pergunta sobre a folha em branco, que é a representação do clichê determinista do que é a escrita acadêmica. A escritura pode, talvez, desafiar as novas e as velhas certezas do que é escrita e leitura na academia? Este foi nosso desafio.
\end{abstract}

Palavras-chave: Escritura; escrita acadêmica; imagem-escrita.

Abstract: During the "Special Topics Seminar: Writing and its combat - the blank sheet", offered in the first semester of 2019 at PPGEdu / UCS, texts that express image-writing emerged. The fight against the cruel side of the blank sheet happened with interventions in the context called academic, Barthes (2000), Deleuze (1997), Guatarri (1987) were present in this game of affection in reading feeding up writing and writing feeding up reading. This game, along with the blank sheet, starts to behave as conditions and possibilities of solitude / silence and of image-affection: these are experiments of writing rehearsed by experimenting with reading and writing. With this experimentation in writing, we asked the question about the blank sheet, which is the representation of the deterministic cliché of what academic writing is. Can writing perhaps challenge the new and old certainties of writing and reading in the academy? This was our challenge.

Keywords: Readwriting; academic writing; image-writing.

\section{Introdução}

Os textos surgem da vida em meio às aulas do Seminário de Tópicos Especiais: Escritura e seu combate - a folha em branco, ocorrido em 2019 e que expressa-imagem-escrita de uma elegância extrema, uma bela voz, talento, e principalmente escritura. As imagens de escritura fazem-se em um tipo de "combate" (COSTA, 2017) afadigam-se pelos ensaios e vão rasgando, aos poucos, a experimentação da folha em branco.

\footnotetext{
${ }^{1}$ Professora da Universidade de Caxias do Sul - UCS, Caxias do Sul. E-mail: srlmatos@ucs.br.

${ }^{2}$ Doutorando da Universidade de Caxias do Sul - UCS, Caxias do Sul. E-mail: roger@ rogercastroeventos.com.br.

${ }^{3}$ Mestranda da Universidade de Caxias do Sul - UCS, Caxias do Sul - UCS. E-mail: cfcavion@ gmail.com.

${ }^{4}$ Mestranda da Universidade de Caxias do Sul - UCS, Caxias do Sul.E-mail: avopacheco@ucs.br.

${ }^{5}$ Professor do Centro Universitário da Serra Gaúcha - FSG, Caxias do Sul. E-mail: rudineir69@gmail.com.
} 
Do combate, o trágico da folha em branco: ela sempre carrega os clichês da palavra de ordem: escrita acadêmica. Combatem-se os clichês, as metanarrativas, a verdade, a repetição do mesmo. Escreve-se para vazar vida: vida-tese, vida-dissertação, vida-estudante. Escreve-se em meio à vida, outro combate. Escritura como experimentação de escrita e de leitura performática, em meio a aula como ensaio (SCHULER; MATOS; CORAZZA, 2014). Escrevese numa captação das intensidades da vida, aquelas que o texto acadêmico só, em sua rigidez normativa, muitas vezes pode não ter suficientes forças para carregar.

Esperamos, inicialmente, diante deste primeiro ensejo, juntarmo-nos à citação de Barthes (2000) que faz tombar em meio às experiências de tornar "fascinante a matéria da qual tratamos" (DELEUZE; PARNET, 1997, s/p), a qual neste texto é tratada como matéria da leitura e escrita de imagem-afecção. Alongamos a presente experiência por meio da Pesquisa Semiótica em rizoma. Assim, este texto tem outra implicação para se inscrever como textoensaio. Ele vem atormentado, definição do escritor Deligny (1913-1996), principalmente quando este afirma que: "l'éducateur est uncréateur de circonstances" (JOSEPH, 2004, p. XIII), o que coloca as intensidades textuais acontecidas durante o Seminário como potências para a percepção de uma outra escrita na universidade.

Nesta intensidade da Pesquisa e do Seminário como aula que ensaia a leitura e a escrita (=escritura) acadêmica, faz-se o jogo de afecção, afetar e ser afetado -aumentando e diminuindo a potência de agir entre os atos de escrever e de ler, pela força entre o silêncio da vida literária e da falação da prescrição da escrita acadêmica. Procedemos nas aulas com as "operações de um sub/sentir, de um entre/sentir, de um intra/sentir, de um extra/sentir, de um trans/sentir, e não, simplesmente, de um re/sentir" (ORLANDI, 2003, p. 93) os textos, as leituras e as escritas denominadas de acadêmicas. Essas operações intensivas compõem-se ao processo de inspiração de escrever e ler, escrita que devora a leitura, leitura que devora a escrita em um processo de coparticipação de uma atitude em outra, que faz com que o leitor, embebido de um texto, tornese um ativo traidor do que leu, apropriando-se do estilo, usando do vocabulário, traficando estruturas e surrupiando a forma para movimentar o conteúdo.

O embate deste jogo de afecção do ler e escrever (=escritura) mobiliza encontros sensíveis ao processo de inspiração que: agarra, fisga, choca, arranha, tomba, afasta, salta, grita, traça, risca. É a violência deste embate que mobiliza a necessidade de pensar, instalando o estranhamento diante do impensado (DELEUZE, 2006a) sobre o escrito. Talvez o embate produza um nível de violência que gera questionamentos, problemas, inquietações, dúvidas para a supremacia do tipo de escrita e leitura denominada acadêmica. Ela vem carregada de clichês do combate da folha em branco, uma militarização do texto que o classifica duramente como seco e imparcial. Mostraremos um pouco deste combate.

\section{Aula como ensaio}

Como questionar os significados já estabelecidos sobre a noção de aula? A imposição é prescrita e determinista na a aula configurar um conhecimento já aprendido pela didática e pela formação de professores. Mas e se desassossegarmos o pensamento da formação de professores nos perguntando pela aula? Podemos dar desassossego ao pensamento de quem pergunta pela folha em branco? Para responder, é necessário o percurso com o encontro da noção de aula como ensaio, o que acontece a partir de um vídeo em formato de entrevista com o filósofo francês Gilles Deleuze. Ele responde a uma série de perguntas da jornalista Claire Parnet. Foram elencados 25 temas mais presentes em sua obra, que são expostos em ordem alfabética com o documento: O Abecedário de Gilles Deleuze (DELEUZE e PARNET, 1997). A entrevista é organizada com a lógica das letras do alfabeto, que indicam os temas a seguir: A de Animal, B 
de Beber, C de Cultura, D de Desejo, E de Enfance (infância), F de Fidelidade, G de Gauche (esquerda), H de História, I de Ideia, J de Joie (alegria), K de Kant, L de Literatura, M de Maladie (doença), N de Neurologia, O de Ópera, P de Professor, Q de Questão, R de Resistência, S de Style (estilo), T de Tênis, U de Uno, V de Viagem, W de Wittgenstein, X de Desconhecido, Y de Indizível e Z de Ziguezague (DELEUZE; PARNET, 1997).

A letra P do alfabeto, a qual traz o tema Professor, aqui muito nos interessa. Dela, retiramos a noção de aula como ensaio e é com esta que nos questionamos sobre a noção de aula e sobre as diferentes ideias que podemos ter em se tratando da intervenção na pedagogia. Colocamos em movimento a pesquisa quando, no vídeo, a jornalista Parnet pergunta ao filósofo sobre suas aulas, até porque ele foi professor durante 40 anos. Deleuze narra sua docência, apontando que ela acontece desde quando lecionava no Ensino Médio até tornar-se professor universitário. Diante das perguntas da jornalista, responde que "uma aula é ensaiada, como no teatro" (DELEUZE; PARNET, 1997, s/p). Para ele, é o ensaio que provoca a inspiração do ensaio da aula. É com o ensaio da aula que ele afirma "considerar fascinante a matéria da qual tratamos" (DELEUZE; PARNET, 1997). E simplesmente diz: “o ensaio é isso" (DELEUZE; PARNET, 1997).

A definição de que "uma aula é ensaiada, como no teatro" (DELEUZE; PARNET, 1997) é parte do teatro de inspiração nietzschiano, ou seja, um teatro que produz um movimento capaz de conduzir o pensamento na dobra da representação. Um teatro que produz movimento ação, porque "o que interessa são os atos" (GUATTARI, 1987, p. 13). O ato que interessa na aula como ensaio é a experimentação, uma vez que, conforme Barthes: "Vem talvez agora a idade de uma outra experiência, a de desaprender, de deixar trabalhar o remanejamento imprevisível que o esquecimento impõe à sedimentação dos saberes, das culturas, das crenças que atravessamos" (BARTHES, 2000, p. 47). Queremos questionar o tema aula, porque com as perguntas genealógicas nietzscheneanas nos forçamos a desaprendermos os saberes e crenças que atravessam a noção de aula transpondo a barreira pré-conceitual que taxa a aula como representação do mesmo e coloca-a em um patamar de experimentos e flertes com a novidade.

\section{Escrita e solidão: silêncio}

Inflexionamos o tema da escrita em direção à frase do autor Deleuze (2006), no livro Ilha Deserta, no texto Sobre as cartas de H. M. (1973), no qual ele indica que: "Nascida da solidão, a necessidade de escrever aos próximos...”. (DELEUZE, 2006, p. 341). Diante dessa breve frase, fazemos uma derivação ao relacioná-la com a formação dos profissionais, defendendo que esse tipo de escrita vibra "um silêncio oco" (ORLANDI, 2012) de ressonância inspiradora e inventiva no território da educação. A necessidade do ato de escrever proveniente da solidão exige uma profissionalização em educação que experimenta "entre a escrita e a ignorância, uma relação ainda mais ameaçadora que a relação geralmente apontada entre a escrita e a morte, entre a escrita e o silêncio". (DELEUZE, 2006a, p. 10). A partir dessa citação, vamos nos ocupar em tratar da relação entre a escrita e a ignorância, até porque o próprio autor demarca que essa é a relação mais ameaçadora. Suponhamos que ela seja uma ameaça para este funcionamento de sociedade já apontado anteriormente e que a ameaça não se encontra nem na escrita e nem na ignorância, mas no que se passa entre a relação. $\mathrm{O}$ entre é a relação de extremidade dos encontros com o silêncio. $\mathrm{O}$ entre requer que "escrevamos na extremidade de nosso próprio saber, nesta ponta extrema que separa nosso saber e nossa ignorância e que transforma um no outro. É só deste modo que somos determinados a escrever" (DELEUZE, 2006a, p. 10). Contudo, a dimensão de escrever derivada da solidão libera práticas inventivas de um outro que ignoramos, um outro que pode constituir um plágio de si, em devir, um constante tomar-se do outro para então experimentar e fazer acontecer a escrita (=escritura). 
E para o pensamento da diferença de Gilles Deleuze, para quê escrever? Ele responde: "escreve-se sempre para dar vida, para liberar a vida aí onde ela está aprisionada no signo da representação. Para isso é preciso que a linguagem não seja um sistema homogêneo, mas um desequilíbrio, sempre heterogêneo" (DELEUZE, 1992, p. 176), um sistema de realidade heterogênea que não se faz atenta somente às normativas. Se a linguagem é sistema em desequilíbrio, com os estudos deleuzianos da linguagem, desequilibra-se o significado universal da representação da escrita, daquilo que é supostamente representado; nunca o escrito vai estar plenamente presente no significado. Ao tensionar o referente da significação, produz-se o efeito do vacilo, o desequilíbrio da representação, isto é, aciona-se o colapso do sistema de significação da relação entre o significante e o significado. Para ele, o significado não é uma entidade mental independente da expressão. O significado (ideia) não está totalmente presente no significante (marca, traço, inscrição, escrita), por isso, o processo de significação não é uma relação de correspondência entre significante e significado, ele é sempre uma operação de diferenciação.

\section{Escritura e imagem-afecção}

Precisamos da imagem-afecção, como a do hexagrama Ch'ien, uma força do oráculo do jogo oriental I Ching. Ela é a força criadora em ação e a experimentação da dimensão-arte do silêncio; para quem escreve na aula como ensaio, a artistagem (CORAZZA, 2010) na escritura deuma vida. A estética criadora é povoada também pelas afecções que investimos no ato de ler e escrever em aula. Tudo acontece experimentando escrita e leitura como partes de extração de singularidade. Esse tipo de experimentação com a diferença “... necessita de toda arte exuberante, dançante, zombateira, pairar acima das coisas” (NIETZSCHE, GC, §107, 2001). Nietzsche tenciona a dimensão da arte e da vida, segundo ele, para não morrermos com a verdade. Seria a arte uma ilusão, por isso não necessitaria ser verdadeira, não trabalharia no jogo da pretensão do que é verdadeiro ou não. Seu jogo é o da criação. (NIETZSCHE, 1992). A arte, neste paradigma, não é representação da vida, mas vivida como um estilo trágico, uma estética de existência, do desgarramento em um fluxo infinito de acabar com prisões, de aprisionar e de libertar a nós mesmos. A força da artistagem está em deixar-se afetar pela existência da não criação. Então, a artistagem pode ser deslocada como práticas inimagináveis, e talvez nem mesmos sendo possíveis de serem ditas, pois ela carrega questionamento dos seus próprios limites pedagógicos e didáticos. É na alquimia artística que nos (des)prendemos da certeza e da verdade pedagógica. Talvez por isso ela seja pura transgressão: transgredir é criar! Para que criar? Para não ser pensado! Cria-se com o fluxo frágil e intenso da experiência corporal de existir, portanto, existindo com as intensidades da vida. A vida aqui tratada como primeiro, como imanência, como processo de forças que se tencionam e se liberam constantemente. Para os pensadores da diferença, primeiro é a vida, com sua vontade de poder, que a faz existir. A seguir teremos três experimentações de escritura na aula que ensaiamos, experimentando a leitura e a escrita:

a) A generalização da vida e da linguagem mata os sentidos sensíveis de produzir a escritura em meio ao que se passa. As escritas formam uma sensação de imagens produzidas aqui. Guiada pela sensação-imagem na duração do seminário, os textos são ensaios de algumas imagens-afecções que foram capturadas pelas forças de quem pesquisa e pergunta pela ruína da escrita acadêmica. O problema violenta a imagem-clichês-folha-branca. Faz-se um exercício de afecção do espírito; um espírito sensível que vive à espreita do alquimista dos espíritos. Ele nos descreve um espírito nada transcendente, mas imanente. Um pesquisador espirituoso, capaz de fazer de sua questão de pesquisa, uma comédia do intelecto. É capaz de dramatizar o logos da escrita acadêmica. Digam-me o que vale? (MATOS, 2017). 


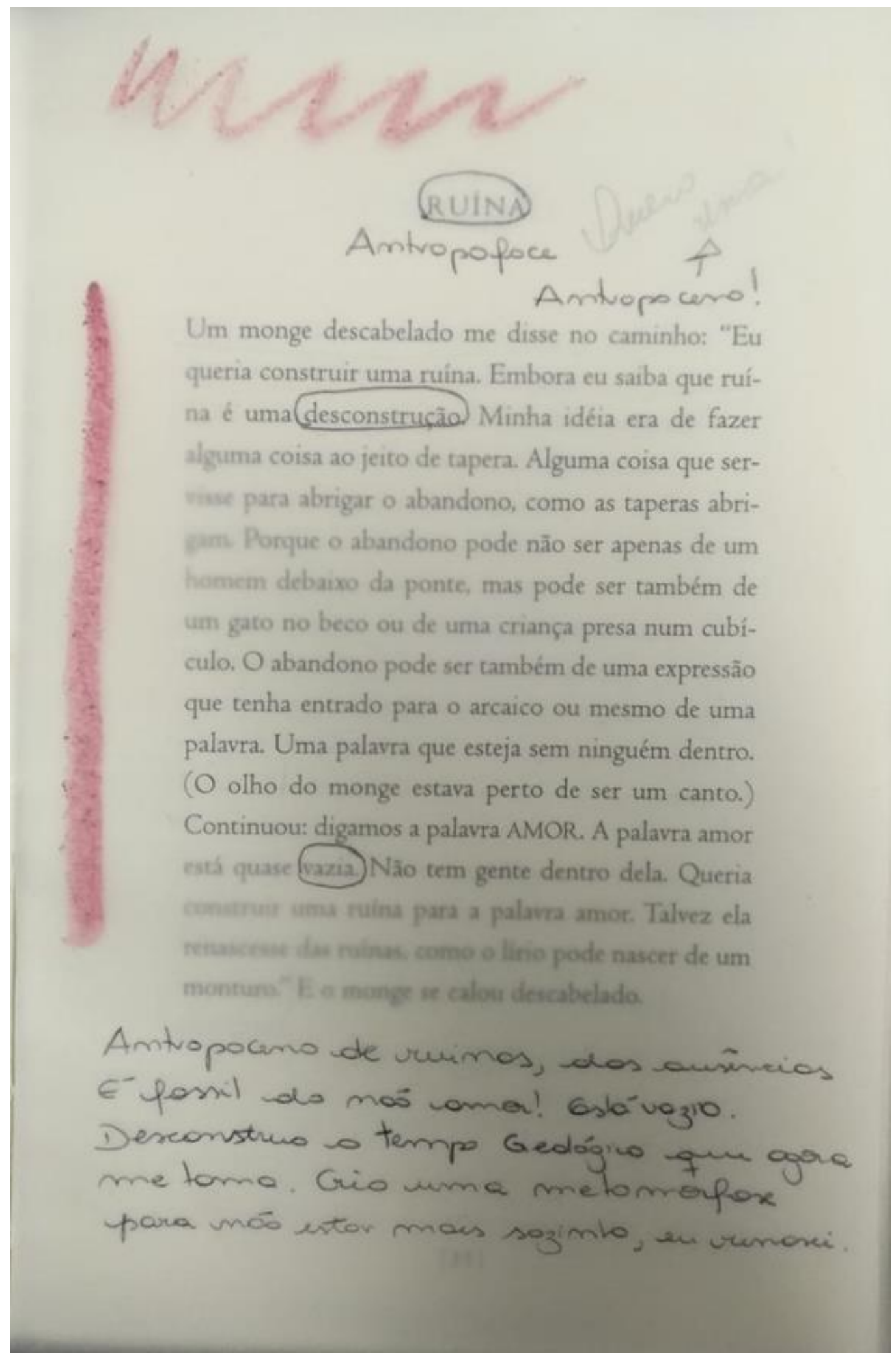

a) Pergunta pela ruína da escrita acadêmica?

b) As imagens-escrituras são escritas de linhas de ação e de inquietação. Na linha da ação, alguns dos signos das imagens-afecção são expressão de corpos que se encontram para criar espaço de pergunta, de problemas que estão implicados e implicantes em meio à vida. A escrita como verdadeira, a escrita acadêmica sofre os efeitos desta sala de aula que ensaia, parte do 
estranhamento com o já sabido. O efeito da pesquisa é a violência do encontro com as forças do já conhecido. O conhecido é sempre violentado, violenta-se o clichê, a folha em branco.

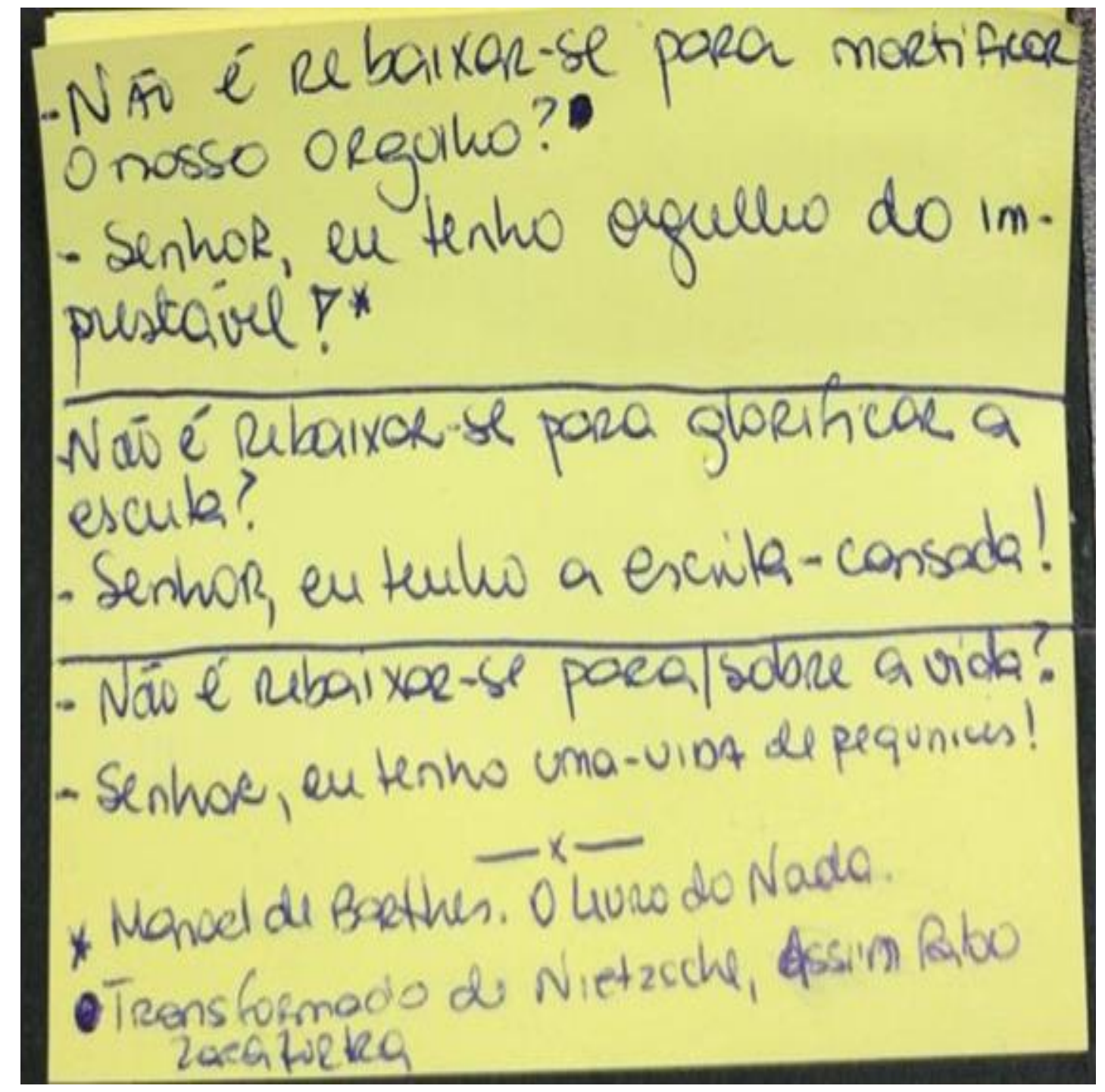

b) A escrita acadêmica sofre os efeitos desta sala de aula que ensaia.

c) O conhecido, o sabido, pensamento-clichê, mesmo para quem pesquisa. A matéria clichê, para o pesquisa(dor) atento pode ser raspada, moldada, crivada, arranhada, cunhada pela força da investigação. Essa pela escritura força o clichê aparecer, porque faz intervalos por dentro do próprio clichê. 


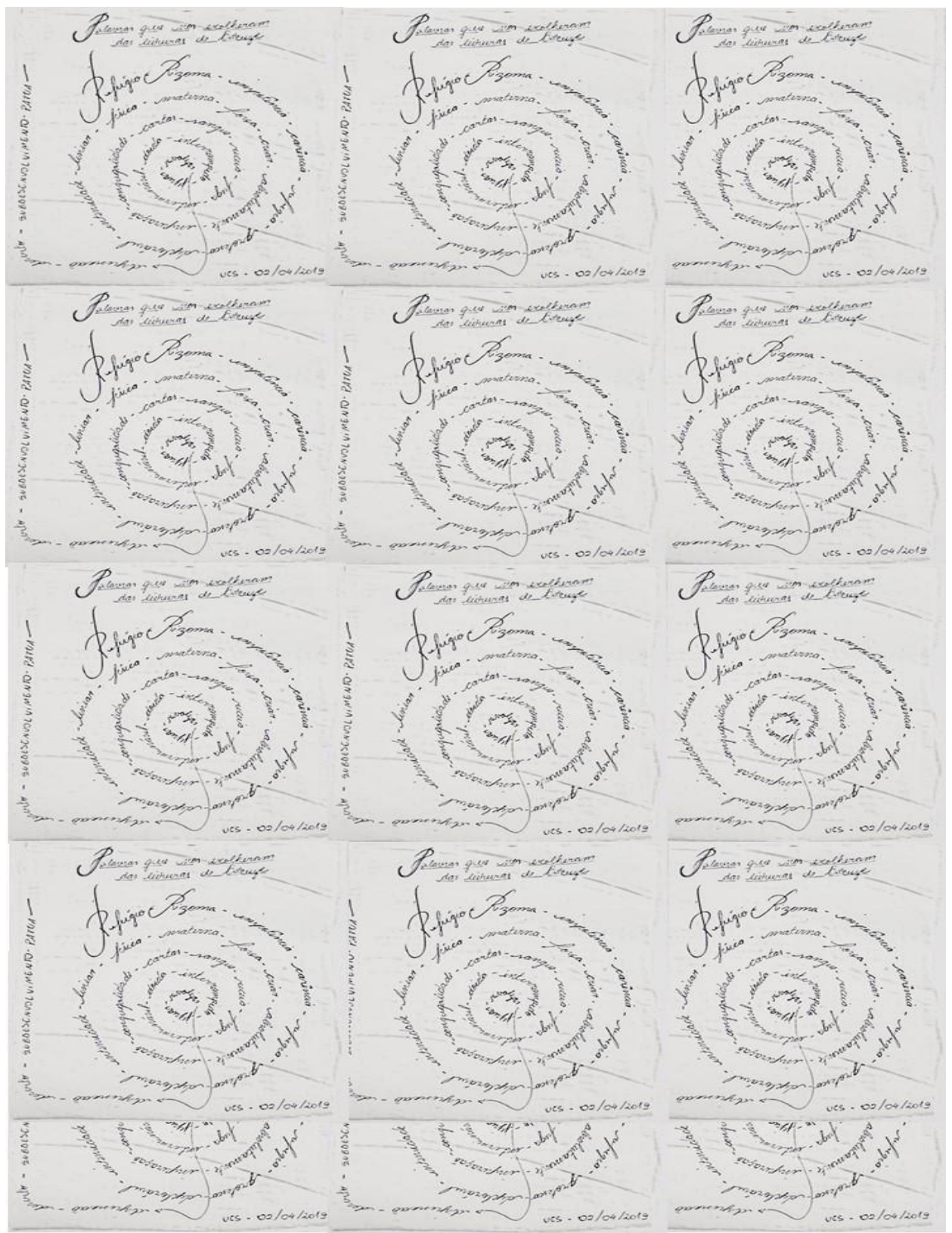

c) A matéria clichê, o pesquisa(dor) atenta a imagem-escritura.

d) Escrevo agora, a visão é tinta sobre o papel. O branco, é papel yseríasatauriques y moçárabes de papel. Não deveriam senão a cutícula, do tempo, a lúnula da unha do tempo, e por isso, escuro, e por isso, escravo, roo a unha do tempo até o sabugo, do refugo, até o sugo e não resgo. A língua ser linguante caminha nas cordas sabendo do não saber do tentar fazer estilando estilizando estilendo a palavrice menor do canto que canta o elogio as coisas.

e) A escrita, atravessada com a diferença, sugere uma forte presença de movimentos de violência. $\mathrm{O}$ texto é, antes de tudo, político: embrenhado em regimes de signos, sujeito à interpretoses infinitas, mergulhado em agenciamentos e ator de uma língua múltipla e cambiante. Uma escrita de caráter combate, resistência, uma escrita-devir. Frente à variação dominante de língua na academia, dão sopros de resistência as formas menores de expressão. Tomando Deleuze e Guattari (2011), a língua somente subjugada aos seus regimes formais e maiores perde possibilidade de potência, vetando a diferença; por outro lado, o trabalho 
naquela própria língua com fim de elevá-la a sua potência expressiva abre possibilidades para que a língua seja explorada de maneiras não antes consideradas; uma língua elevada a sua potência; uma escrita experimentação.

f) Escritura contornam sentidos distintos, um toque de sensibilidade, talvez um clamor artístico pela criação, retravando novas línguas e trazendo elementos terceiros para construção de histórias ou palavras, enquanto a segunda caracteriza-se por ser mais rígida, com destaque para o seu teor linguístico, principalmente, o falar sobre algo ou alguém.

g) O nobre evento, também convida a fazer devorações sugeridas pelos conceitos que faz cena de escrita-vida: "para liberar a vida aí onde ela foi aprisionada" (uma das frases-clichês, que atormentamos Deleuze e Guattari). Uma escrita que se estica para expressar as intensidades, afinal: "Escrever é talvez trazer à luz esse agenciamento do inconsciente, selecionar as vozes sussurrantes, convocar as tribos e os idiomas secretos, de onde extraio algo que denomino Eu [Moi]. (DELEUZE e GUATTARI, 2011, p. 18).

h) Uma escrita acadêmica que transita pelos meandros da experimentação artistando com as possibilidades de uma linguagem que recolha estados intensivos revelando possibilidades. A escrita acadêmica do Seminário passa por saber que os momentos da escrita formativa e normativa, com nuances fascistas que ditam regras e prescrições ocupam seu espaço na Universidade, todavia há possibilidades de escritura que, por não se encaixarem nos modelos ditos maiores pela Academia, acabam ficando na sombra. É das ranhuras e gotículas dos textos roubados e escritos fugidos do sistema que esta outra escrita, não mais nem menos acadêmica, se faz - dentro da minoria de estar perdida no invalor de seu crédito.

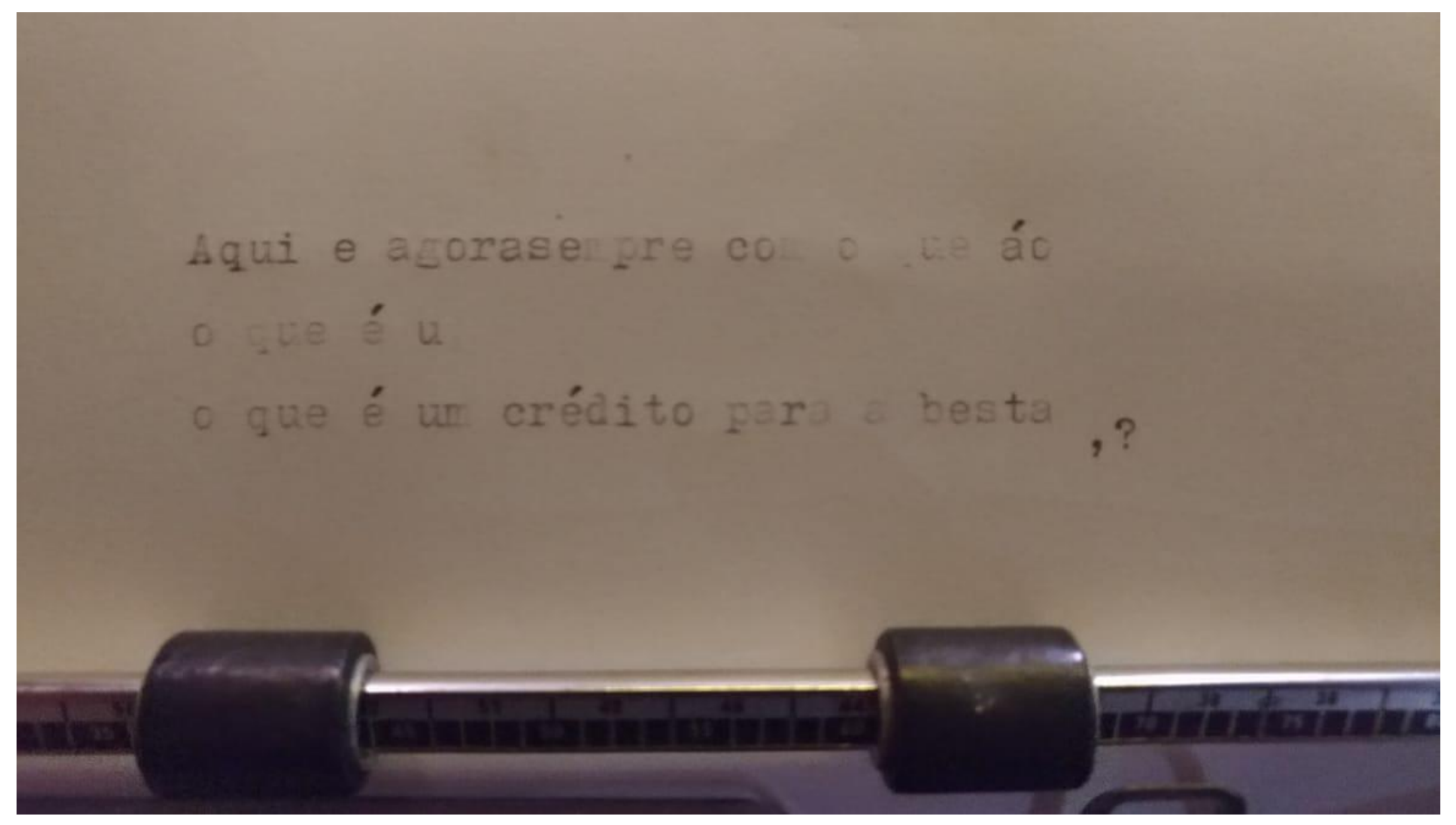

i) Escrita como forma de combate. Escrever para combater, pois se a escrita representa um poder, uso-a então para ir contra o sistema de representações que acomoda, para escancarar o que está fechado. Pensar, escrever, ler, ensinar a ler, ensinar a escrever. São ações de fuga, de "devir" 
para romper. "A escrita é à mão, é portanto o corpo: suas pulsões, seus controles, seus ritmos, seus pensamentos, seus deslizes, suas compilações, suas fugas...” (BARTHES, 2004, p. 275).

j) Aula, primeiro semestre de 2019: Escritura e seu combate - a folha em branco. Ambiente institucional que promove o rompimento de clichés. Abrindo para possibilidades de pensamento além dos estabelecidos e acomodados no corpo por anos de escolarização. Busca pelo prazer através da leitura e da escrita. Desmembramentos de textos para (re)significálos. Apropriar-se de termos e ideias do autor; reescrever, repensar, conversar, olhar, rir, juntar-se ao meu e ao outro. Leitura morta, tornando-se leitura viva (BARTHES, 2004a). Do abstrato e inatingível estado de poder, para o acessível e possível. Estado de quem se apodera do poder da leitura e da escrita, e sente-se capaz de seguir sem limites.

\section{Conclusão}

Com essa experimentação de escritura, movimentamos a pergunta sobre a folha em branco, que é a representação do clichê determinista do que é a escrita acadêmica. Este conceito totalizador ameaça a possibilidade de aprisionarmos a vida da pesquisa e do pesquisador em somente uma escrita aceita e aplaudida como acadêmica. Por isto, perguntar pela folha em branco faz com que perguntemos pela leitura e escrita como práticas de inventividade. A escrita pela escritura ganha espaço (po)ético na aula como ensaio, no Seminário do PPGedu/UCS. Disciplinar a escrita acadêmica? Nos perguntávamos se o clichê da folha em branco carregava a representação do que é este disciplinamento... A escritura pode, talvez, desafiar as novas e as velhas certezas do que é o ato da escrita e da leitura na academia? Este foi nosso desafio. Mostramos um pouco de nossa experimentação, de nossa política e poética, acompanhamo-nos com a experimentação literária de alguns escritores. As experimentações funcionaram como signos não codificados de leitura e de escrita, por isso produzem estranhamento inventivo. O movimento de estranhar é pura insegurança, é descontrole, por isso fazem-se aberturas a outros afectos (DELEUZE, 1992). Afectos que a instituição escolar tirou do corpo, uma vez que fomos domesticados a escrever sempre norteados por um padrão de estrutura, estilo e até de vontades. O corpo da afectação é fluxo frágil e intenso, que foi roubado pela sociedade disciplinar e de controle. Talvez as intensidades do corpo movam outras experimentações. Existir pela diferença potencializa os desconhecidos, as práticas ainda não pensadas, nem imaginadas. $\mathrm{O}$ afecto é ação de ser afectado pela criação, isto dá insegurança! A criação é novidadeira! A criação é diferente! Para que criar? Para não ser pensado! Cria-se com o fluxo intenso da experiência corporal de existir, portanto, existo com as intensidades com a vida. A vida aqui tratada como primeiro, como imanência, como processo forças que se tencionam a relação entre o clichê da escrita acadêmica e a experimentação literária. Digam-me o que vale? (MATOS, 2017).

\section{Referências}

BARTHES, Roland. Aula. Trad. Leyla Perrone-Moisés. São Paulo: Cultrix, 2000.

BARTHES, Roland. O grão da voz. Trad. Mario Laranjeira e Ligia F. Ferreira. São Paulo: Martins Fontes, 2004.

BARTHES, Roland. Inéditos, vol. 1: teoria. Trad. Ivone C. Benedetti. São Paulo: Martins Fontes, 2004a. 
CORAZZA, Sandra Mara. Para pensar, pesquisar e artistar a educação: sem ensaio não há inspiração. Revista Educação, p. 68-73, 2010 [Especial Biblioteca do Professor. Deleuze pensa a Educação. A docência, e a filosofia da diferença].

COSTA, Luciano Bedin. Ainda escrever: 58 combates para uma política do Texto. São Paulo: Lumme Editor, 2017.

DELEUZE, Gilles. Conversações - 1972-1990. Trad. Peter PálPelbart. Rio de Janeiro: Editora 34, 1992.

DELEUZE, Gilles. Os intelectuais e o poder (com Michel Foucault) 1972. In: DELEUZE, G. Ilha deserta e outros textos (1953-1974). São Paulo: Iluminuras, 2006.

DELEUZE, Gilles. Diferença e repetição. Tradução Luiz Orlandi e Roberto Machado. 2. ed. Rio de Janeiro: Editora Graal, 2006a.

DELEUZE, Gilles; GUATTARI, Félix. Mil Platôs: capitalismo e esquizofrenia, vol. 2. Trad. Ana Lúcia de Oliveira e Lúcia C. Leão. 2. ed. Rio de Janeiro: Editora 34, 2011.

DELEUZE, Gilles; PARNET, Claire. L'Abécédaire de Gilles Deleuze: entrevista com Gilles Deleuze. Paris: EditionsMontparnasse, 1997. [Editoração: Brasil, Ministério de Educação, Programa TV Escola, 2001]. Disponível em: https://drive.google.com/file/d/1t1lpELH79fCeOCJh8wYG5Dl5fRGQp3o0/view. Acesso em: março 2020.

GUATTARI, Félix. Somos todos grupelhos. In: GUATTARI, F. Revolução molecular: pulsações políticas do desejo. Trad. Suely B. Rolnik. 3. ed. São Paulo: Editora Brasiliense, 1987. p. 12-19.

JOSEPH, Isaac. Préface. In: DELIGNY, Fernand. Graine de crapule: conseilsauxéducateursquivoudraientla cultivar suivi de lesvagabondsefficaces et autrestextes. France: Malakoff, 2004, p. VII-XIII.

MATOS, Sônia Regina da Luz. Diga-me o que vale? Alegrar, n. 20, p. 95-104, 2017, [Dossiê: Outras partituras. Poéticas do movimento].

NIETZSCHE, Fredrich. O nascimento da tragédia ou helenismo e pessimismo. Trad. J. Guinsburg. São Paulo: Companhia das Letras, 1992.

NIETZSCHE, Frderich. A gaia ciência. São Paulo: Companhia das Letras, 2001.

ORLANDI, Luiz. Signos proustianos numa filosofia da diferença. In: OLIVEIRA, Sergio Lopes; PARLATO, Erika Maria; RABELLO, Silvana. (Org.). O falar da linguagem. São Paulo: Lovise, 2003. p. 15-123.

ORLANDI, Luís. Elogio à "arte do encontro e da composição: Espinosa + Currículo + Deleuze”. Conferência na Faculdade de Educação. UNICAMP. 30 de maio de 2012. 
SCHULER, Betina; MATOS, Sônia Regina da Luz; CORAZZA, Sandra Mara. Experimentações de escrita, leitura e imagens na escola. Caderno de notas 6. Porto Alegre: Universidade Federal do Rio Grande do Sul, 2014. 